\title{
Sperm donor suffers years later from inherited disease
}

\author{
D O E Gebhardt
}

Dutch press sympathetic to handling by hospital of discovery that a sperm donor was suffering from an inherited disease

O n February 27th 2002, Dutch newspapers reported a serious mishap at a hospital in Den Bosch. An apparently healthy sperm donor during 1989 to 1995 informed the hospital in 1997 that he had recently been diagnosed as suffering from autosomal dominant cerebellar ataxia (ADCA) of which he was unaware when donating the sperm. The severely disabilitating neurological disease, which has a very low incidence, does not occur before puberty and may remain latent for many years. It has been established that $50 \%$ of the children from a parent with ADCA will also inherit the disease. The director of the hospital immediately informed the inspector of the Ministry of Health that 18 children had been conceived with the sperm in 13 women. The director did not tell the parents of the genetic disease of the sperm donor until three years later, because he first needed the advice of geneticists, ethicists, and lawyers.

This mishap was waiting to happen. Now that it has taken place, it is of interest to review the reactions in the Dutch press. First of all, it is notable that none of the authors (including editors and science journalists) blamed the director, F Croonen, of the hospital in Den Bosch or its staff for the occurrence of this tragic event. They also did not reproach them for telling the parents what happened.

On the 27th of February 2002, The Volkskrant reported that this incurable disease, (ADCA), which was spread by the use of sperm from a donor, could not be detected by genetic tests. The first symptoms, which are caused by the gradual shrinking of the cerebellum, are a disturbance in speech and locomotion. In the article, the director is reported as saying: "After the diagnosis was confirmed, intensive consultations were held with a number of Dutch geneticists and ethicists. These consultations took some time, but we wanted to present the parents with sound information. It is of course bad news and you cannot offer them any consolation. We also had to inform their general practitioner. Medically speaking there was no reason to make haste to inform the parents. The children are all still young (between seven and 13 years) and the disease will not appear for some time". Director Croonen believes that it was just bad luck. "Anyone who has children can pass on a genetic disease. What makes the

\begin{abstract}
A case is described of a man who discovered years after donating sperm for artificial insemination, that he had a serious genetic disease, autosomal dominant cerebellar ataxia (ADCA). This manifests itself only years after puberty and occurs in $50 \%$ of the progeny. The sperm had been used for the conception of 18 children in 13 women. The parents were only told three years after the insemination. This long time interval was unavoidable since many of the parents had to be found and the hospital director wished first to discuss the matter with his legal advisors and other experts.

In future, in agreement with the new law only 10 inseminations will take place with sperm from one donor. This will reduce still further the availability of donor sperm.
\end{abstract}

calamity so unique is the fact that so many children (18) have been conceived. Another problem is that not all of the parents have told their child that his or her father is not the biological father." In this article, the fertility expert and chairman of the sperm banks in Holland and Belgium, Dr P Janssens said: “Nowhere is donor sperm tested for genetic abnormalities. It is, however, tested for the occurrence of AIDS, hepatitis C, and some venereal diseases. The donor is also questioned about his health and whether hereditary diseases occur in his family. Sperm used for artificial insemination is, in fact, safer than your or my sperm."

In the same newspaper, one day later, Dr Janssens said that in general the sperm of one donor is used for the conception of 25 children. Once the new law on artificial insemination with donor sperm is approved by parliament, this number will, however, be reduced to 10 . Also the name of the biological father will, under certain circumstances, become available to the child.

In The Volkskrant of the 28th of February 2002, two journalists write that a donor wished to contact the children conceived with his sperm, but heard that his file had been destroyed. This is because in Holland medical files need only be kept for 10 years. Croonen said that in his hospital the files of sperm donors were kept much longer.

In Trouw of 28th of February 2002, Croonen reported that most experts advised him to tell the recipients of the sperm what had happened. But some experts had reservations about this frankness, even if this meant that the child did not know that it could pass on the disorder on reaching maturity and conceiving children. Croonen also had difficulties in tracing some of the couples who had a child obtained with sperm of the ADCA donor. The privacy rules made it impossible to use the town records. Fortunately, the privacy regulations have changed recently and it is now possible for hospitals to obtain the addresses of anyone who has been treated there.

Croonen has no regrets that the parents were only informed three years after he had been told what had happened: "Thus we gave the parents three years of blissful ignorance. However, if a similar case should occur again, we would not wait so long."

The medical ethicist G de Wert, (Trouw 27th of February 2002) believes that once a test for diagnosing ADCA is available, the child and not the parents should determine if the test should be used. This is because the child also has the right, if so desired, not to know whether it has a genetic disease.

So far only one ethicist (D Egberts, Algemeen Dagblad (1st of March 2002) has mentioned the medical principle of primum non nocere and raised the question of whether the whole procedure of artificial insemination should be reconsidered. The editor of Trouw (lst of March 2002) on the other hand concluded: "Sperm without a risk does not exist. Neither from a donor nor from a man who has a natural relationship. And even if in the distant future a safe technique is developed to determine genetic aberrations, it is doubtful if its use is desirable."

J Med Ethics 2002;28:213-214

Author's affiliation

D O E Gebhardt, Anna van Burenlaan 1, 2341 VE Oegstgeest, The Netherlands; doe.gebhard+@planet.nl 


\section{-.......}

Gebhardt reports the tragic circumstances of a sperm donor who fathered 18 children in 13 women, who subsequently was diagnosed with autosomal dominant cerebellar ataxia (ADCA). ${ }^{1}$ The ADCAs are a genetically heterogeneous group of conditions that overall affect fewer than one in ten thousand people. ${ }^{2}$ Currently 16 locations on chromosomes have been found where genes reside that have mutations resulting in ADCAs. Testing is generally available for 5 (SCA 1, 2, 3,6 , and 7). Testing for the common CAG expansion (the type of mutation in these five genes that lead to ADCAs is the presence of three bases $\mathrm{C}, \mathrm{A}$, and $\mathrm{G}$ that repeat over and over, CAG CAG CAG etc) in these five genes will identify the genetic cause in about half of all families affected by ADCA. ${ }^{3}$ The offspring of the sperm donor are at $50 \%$ risk to inherit the mutation and therefore go on to develop the condition. Autosomal dominant cerebellar ataxia usually has its onset in adulthood and causes progressive unsteadiness (ataxia) with the sufferer generally becoming wheelchairbound and ultimately dying from the condition around 10-30 years after the onset. $^{2}$

Could this episode have been prevented? In all donor gamete programes, a thorough family history should be taken to detect the risk of such occurrences. In the case described, it is possible that the gentleman was unaware of the family history-for example, because he was adopted, or that his family history was apparently negative due to the genetic mechanism of anticipation. Anticipation is well described for some of the ADCAs and refers to the phenomenon whereby the age of symptom onset is earlier in successive generations. The chances of an individual having a mutation in one of these genes and not knowing of his family history is extremely small and does not justify routine testing in gamete donors. In 1995 when the last of his donor offspring were conceived, only SCA 1 and 3 had been discovered to be the cause of ADCA.

In my view it was entirely appropriate to let the families of the children conceived through the sperm donor know about their children's risk. The three year delay is unlikely to have resulted in harm but if the information had been leaked to the media prior to the families being notified, it could have caused considerable anxiety to many couples who utilised that clinic's donor sperm service. Whilst there are no treatments that are currently known to delay the onset or slow the progression of ADCAs, this may change over the coming years. The oldest child is now 13 years, meaning that the children will be of an age where they may reproduce over the coming five years and beyond. They may wish to have predictive genetic testing to assist with reproductive decision making if a causative mutation has been found in the gentleman. Similarly the children may avail themselves of predictive testing to assist in lifestyle decisions. This testing should in my view, only be undertaken if the child wishes to have this information and is at an age that he or she can make an informed choice about this. ${ }^{4}$

There is general agreement that gamete donors should be screened for recessive conditions that are common in that population as well as a chromosome study being performed. Examples of recessive conditions that should be screened for are cystic fibrosis in the white population, thalassaemia in Asian and Mediterranean groups, and Tay Sachs disease in those of Ashkenazi Jewish background. ${ }^{5}$ Tizzano and colleagues described a situation which reinforces the importance of these recommendations. ${ }^{6}$ This involved a condition known as spinal muscular atrophy (SMA) which causes a child to progressively lose muscle strength due to deterioration of the nerves that supply the muscles. It is often fatal before the second birthday. The condition is recessively inherited which means that a gene mutation is inherited from each parent. It affects about one in 10000 people. In the situation described by Tizzano and colleagues, a woman conceived using donor sperm and the resultant child was affected by SMA. She then conceived again with sperm from a different donor and tragically the second child was also affected by SMA. The authors recommend that consideration should be given to routine screening for carrier status (about 1:50 whites are carriers of SMA) for SMA in gamete donors by undertaking a cost-benefit analysis.

What should happen in the coming years when DNA technology becomes faster and cheaper, meaning that gamete donors may be able to be screened for numerous genetic mutations? For recessive disorders, carrier testing is associated with a low risk of significant sequelae for a positive result which generally has no implications for the gamete donor's own health. This is because in recessive inheritance the parents have one mutation in the pair of genes but the second unaffected gene compensates, meaning that person's health is in no way affected by carrying that mutation. It is estimated that all people have 5-10 recessive mutations and they are only a problem if that person's partner carries a mutation in the same gene. If the gamete donor is a carrier of a recessive mutation then the recipient can be tested and if they are a carrier of a mutation in the same gene, then clearly that donor's gametes should not be used.

To find that one is going to develop a fatal neurodegenerative condition whilst undertaking a selfless act such as gamete donation is another matter entirely. This is the situation if a dominant mutation is found. In dominant conditions, having a mutation in one of a pair of genes is sufficient to result in the disease occurring, as is the case with ADCAs. I expect that improved technology will result in a broad range of recessive conditions being screened for in gamete donors. However, the low chance of finding a severe dominant condition in the absence of a family history together with the potential harm to the donor, not to mention the fact that it may well discourage people coming forward as donors, should mean that conditions such as the ADCAs will not be screened for, even if tests are available. Time will tell!

J Med Ethics 2002;28:213-214

\section{Author's affiliation}

Martin Delatycki, Neurogenetics Service, Genetic Health Services Victoria, Murdoch Childrens Research Institute, Royal Children's Hospital, Flemington Road Parkville, 3052. Victoria, Australia;

delatycm@cryptic.rch.unimelb.edu.au

\section{REFERENCES}

1 Gebhardt DOE. Sperm donor suffers years later from inherited disease. Journal of Medical Ethics 2002;28:215-6.

2 Stevanin G, Durr A, Brice A. Clinical and molecular advances in autosomal dominant cerebellar ataxias: from genotype to phenotype and pathophysiology. European Journal of Human Genetics 2000;8:4-18.

3 Storey E, du Sart D, Shaw JH, et al. Frequency of spinocerebellar ataxia types 1 , $2,3,6$, and 7 in Australian patients with spinocerebellar ataxia. American Journal of Medical Genetics 2000;95:351-7.

4 Delatycki M, Tassicker R. Adult onset neurological disorders: predictive genetic testing. Australian Family Physician 2001;30:948-52.

5 Barratt C, Englert Y, Gottlieb C, et al. Gamete donation guidelines. The Corsendonk consensus document for the European Union. Human Reproduction 1998;13:500-1.

6 Tizzano EF, Cusco I, Barcelo M, et al. Should gamete donors be screened for spinal muscular atrophy? Fertility and Sterility 2002;77:409-11. 